Received: January 8, 2018

Revision received: May 2, 2018

\title{
Construction of Industrial Design Education System with Consideration of Chinese and Western Cultural Integration and Counter-Measure Analysis
}

\author{
Changhong Chen \\ Shijiazhuang Tiedao University
}

\begin{abstract}
In order to cultivate industrial design talents needed in China, we should enhance educational programs on industrial design from varied aspects. This paper analyzes the construction of industrial design education system and counter-measures, compares the Chinese and western industrial design education systems from three aspects, i.e., curriculum, teaching mode and evaluation. Through in-depth analysis, this paper concludes that the Chinese educational system for industrial design has the deficiencies of lack of featured curriculum, homogeneous teaching mode, and lack of personalized standards and objectivity and impartiality in evaluation. Considering the actual conditions of the industrial design education in China and advanced teaching concepts of from the west, we have proposed advices and suggestions for improving industrial design teaching programs from three aspects, by setting up featured curriculum, improving teaching mode, and establishing diversified and personalized evaluation standards. This research provides valuable and practical insights for improving the system of industrial design teaching in China.
\end{abstract}

\section{Keywords}

Chinese and Western Industrial Design Teaching • Curriculum • Teaching Mode

- Teaching Evaluation System

School of Mechanical Engineering, Shijiazhuang Tiedao University, Shijiazhuang 050043, China. E-mail: $958691206 @$ qq.com

Citation: Chen, C. H. (2018). Construction of Industrial Design Education System with Consideration of Chinese and Western Cultural Integration and Counter-Measure Analysis. Educational Sciences: Theory \& Practice, 18(5), 1968-1975. http://dx.doi.org/10.12738/estp.2018.5.096 
In order to meet economic development goals, China is on a fast track towards new-type industrialization. Industrial design talents with innovative capacity are the driving force to fuel the development of such development. Under the backdrop of economic globalization, in order to satisfy domestic needs for industrial design talents and catch up with global standards, it has emerged as a focal point in the eyes of researchers and industry experts to establish an industrial design education system and to cultivate human resources in this area.

Industrial design is driven by creativity. It integrates technological innovation with art in an organic way, and develops product designs under the pre-condition of industrialization (Yang, You \& Chen, 2005). Subject to influences of multiple factors, industrial design education is at varied development phases around the world, resulting in a highly skewed situation. In the west, industrial design has a long history, and along with it, the educational programs in this regard. The USA has the best industrial design education system in the world, with first introduction of such programs in 1925. Now it has 49 universities, public, private or independent, offering industrial design educational programs in the States (Hutchison, 1964). In the UK, a country of origination of industrial design, teaching system on the topic is well-established, with high importance attached by the government and generous fiscal funding (Mahmoud, 1964). China did not have any industrial design education until the foundation of the People's Republic of China. In the 1980s, industrial design education in China came to the attention of the companies and government, and from then on, it started to catch up on the development. Now China has in place a sizable industrial design education. But due to the restraints of varied economic development rates in China, resources of industrial design education concentrate in the developed areas with industrial strength. By making comparisons between the Chinese and western industrial design education, we identified that there is a substantive gap in teaching outcome between Chinese and the western countries in terms of teaching outcomes, though overall the teaching scale is significant in China (Naveiro and Pereira, 2008).

Based on this, the paper sets to introduce the western industrial design teaching concepts into the Chinese system, and analyze the system construction and counter-measures for China's industrial design teaching. It conducts comparison between the Chinese and western teaching systems from aspects of curriculum, teaching mode and evaluation system. And based on the analysis, it proposes advices and counter-measures on improving the Chinese system with consideration of advanced teaching concepts from the west on industrial design teaching.

\section{Comparative study between Chinese and western industrial teaching systems}

\section{Comparative study on curriculums}

Chinese curriculums. This paper analyzes industrial design curriculums among varied Chinese universities. We have observed that though with some variances in curriculums among these universities and colleges, fundamentally, they are based on the early experiences of domestic art programs, and are subject to changes and adjustments. This paper selects curriculum from the undergraduate industrial design program of Zhejiang University for analysis. Table 1 shows the division of courses and their proportions of industrial design curriculum system (Yao, 2015). 
Table 1

Division of Industrial Design Curriculum System of Zhejiang University

\begin{tabular}{ll}
\hline General education course (44\%) & Basic compulsory course \\
\cline { 2 - 2 } Professional Courses $(41 \%)$ & Basic elective course \\
\hline Practical course $(15 \%)$ & Professional compulsory course \\
\hline
\end{tabular}

Fig 1 shows how many credits the general courses, professional courses, and practical courses take up for 4-year undergraduate programs.

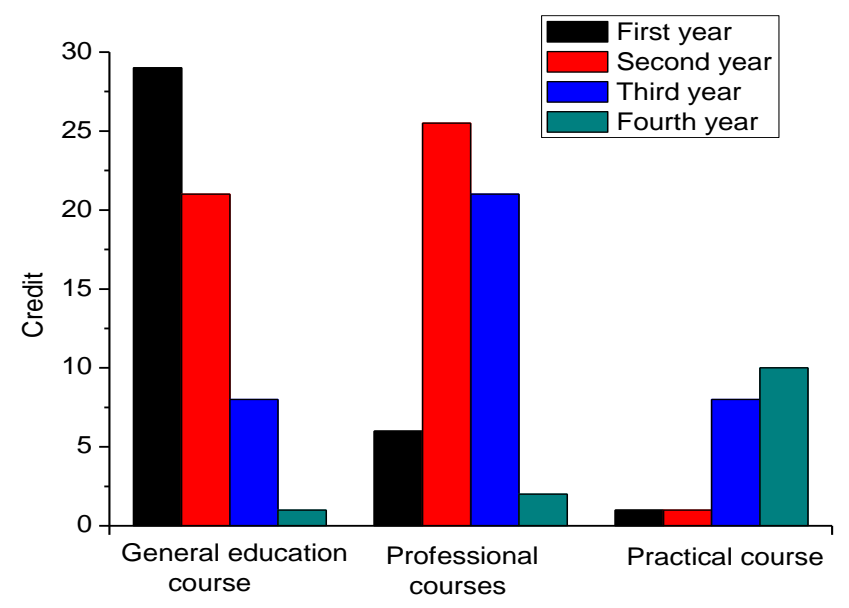

Figure 1. Three-part course undergraduate stage distribution map-Zhejiang University

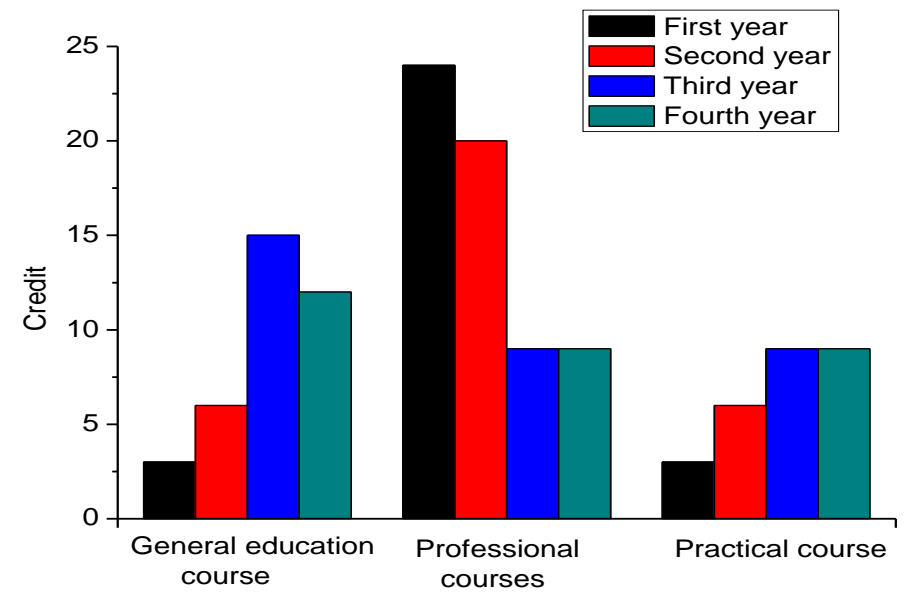

Figure 2. Three-part course undergraduate stage distribution map-Duisburg-Essen University

Western curriculum. This paper selects University of Duisburg-Essen in German for the curriculum study. Different from the Chinese curriculum, in the German system, professional courses take up 50\% of the total 
curriculum, general courses $29 \%$, and practical courses $21 \%$. Fig 2 includes the distribution of these courses in a four-year undergraduate program (Tenorio, Maia \& Grant-Tenorio, 2002).

\section{Comparative study of teaching modes}

Chinese teaching mode. The Chinese mode for industrial design teaching includes two phases (Sener \& Kotch, 2007). In the first phase, the conventional art education mode was adopted, featuring imitation and sketching. And in the second phase, the German and Japanese style of "three parts of design" was implemented to form a "three-part" teaching mode featuring modeling foundation, basics of design, and professional design. As in Fig 3, this teaching mode has an integral design, facilitates offering of teaching activities, and meets the requirements for bulk production. So there are many universities and colleges, to this day, who are still using this mode. In recent years, some of them have tried to implement a "project-based" approach, and integrated teaching courses, from the elementary to the profound, on industrial design, based on the "three-part" teaching mode. In this way, they help students enhance their design capacities through completion of projects and acquisition of knowledge.

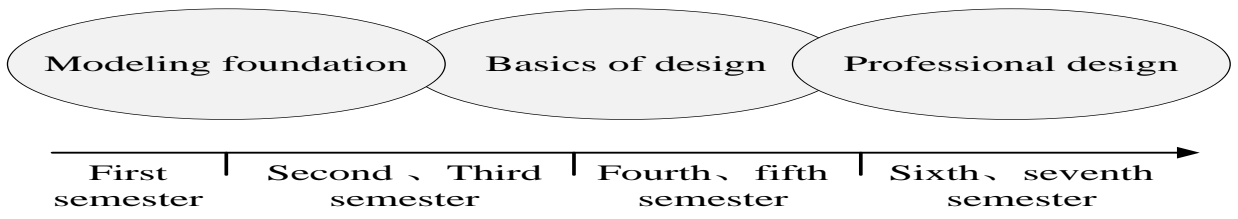

Figure 3. Schematic diagram of the "three-stage" teaching mode

Western teaching mode. The German teaching mode stands out for practicality and technicality. The discussion-based teaching mode is the most widely adopted among the German universities for being inspiring and research-friendly. The discussion-based mode includes case interpretation, field trip, team project, and problem-based teaching (Hu \& Cardin, 2015). This approach is believed to be helpful in enhancing comprehensive competitiveness in students.

\section{Comparative study of teaching evaluation}

Chinese teaching evaluation system. Evaluation is an integral part of teaching as a process to determine value of teaching activities. A well-established evaluation system on the industrial design curriculum has been in place since the 2001 teaching reform in China. The process evaluation is given due attention, and the content is on a track of comprehensive evaluation rather than knowledge assessment. The evaluation approach is increasingly diversified featuring "quantitative and qualitative" evaluation. Table 2 includes an example (Boks \& Diehl 2006).

Table 2

An Example of a Combination of "Quantitative and Qualitative” Evaluation Methods

\begin{tabular}{lll}
\hline Evaluation project & Fraction ratio & Score \\
\hline Relationship between topic selection and course content & $10 \%$ & - \\
Content and results & $70 \%$ & - \\
The logic, structure and language of the paper & $10 \%$ & - \\
Paper format, reference format & $10 \%$ & - \\
\hline
\end{tabular}


Western teaching evaluation system. Key goals of the German teaching evaluation system are to enhance learning environment and confidence in students. It is a combination of process evaluation and summative evaluation, with focus on reflecting students' learning process (Zainol et al., 2015). In order to cultivate the habit of self-reflection in students, self-evaluation by students is part of the teaching evaluation system.

\section{Comparative study of Chinese and western systems}

The western industrial design teaching system considers both the market and teaching, so the universities have set up curriculums with their own features. But in China, as industrial teaching is in an initial stage of learning, universities tend to have highly homogeneous curriculums. We also identified gaps in developing students' practical skills, communication capacity, and innovation between the Chinese system and the western system.

In terms of teaching mode, China is underperforming in terms of insufficient investment on teaching infrastructure, uniform and one-sided teaching materials, and restrained faculty resources. It is also witnessed discrepancy of teaching goal and society's needs, as well as simple teaching methods.

In terms of evaluation mode, the summative evaluation is dominant in the Chinese system. There is certain level of discrepancies in process-based evaluation, along with fade zones observed in assessment standards. For the purpose of evaluation, value in student's personalized development is oversighted.

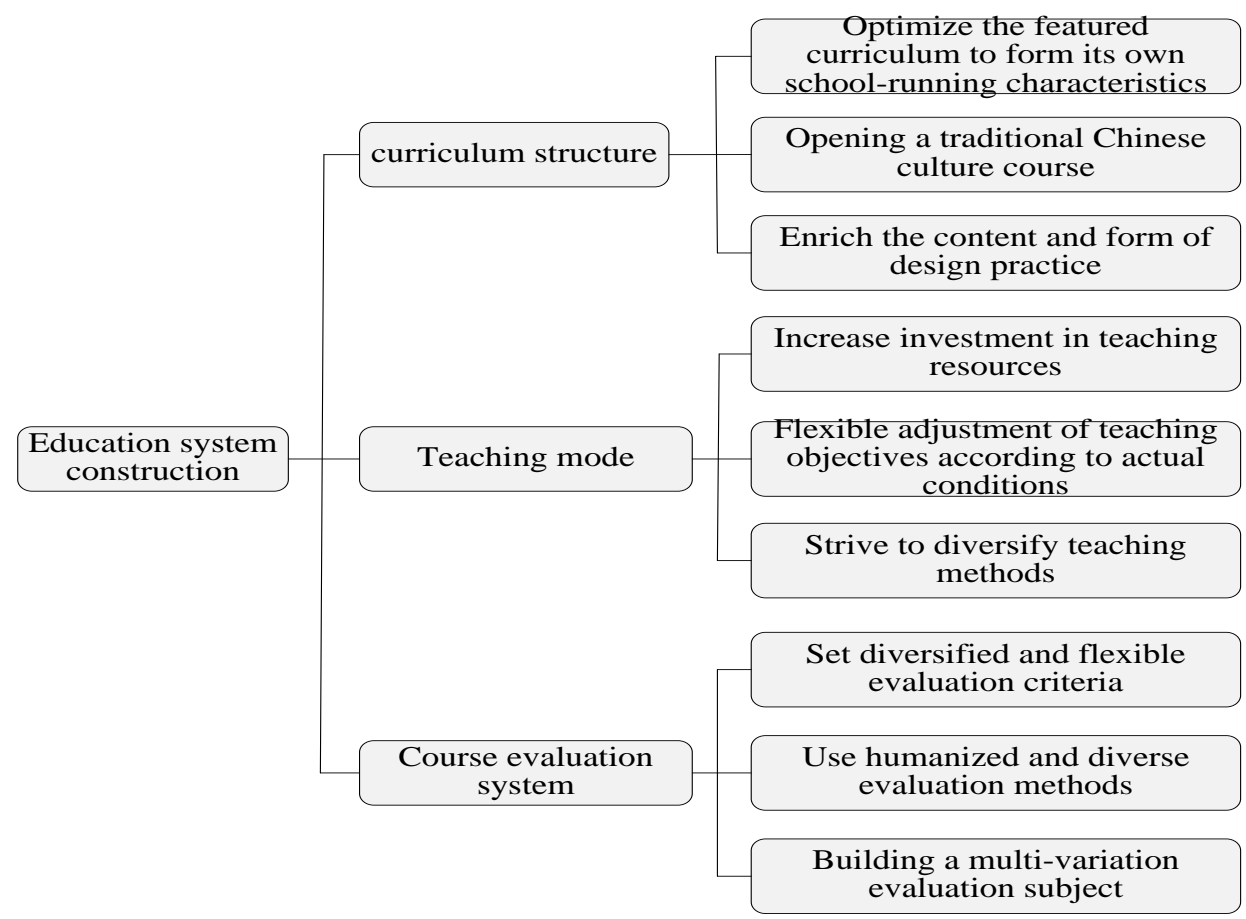

Figure 4. Education system construction and countermeasures 


\section{Industrial design teaching system construction with consideration of Chinese and western cultures and counter-measure analysis}

Based on the above analysis of the Chinese and western systems, we thereby propose advised improvements on the Chinese industrial design education system below considering the advanced western teaching concepts. The details can be found in Fig 4.

Optimization of Curriculum of Chinese and Western Cultural Integration and Counter-Measure Analysis

Optimize featured curriculum to form its own characteristics. Universities in China should set up courses in line with the cultural, economic, and geographic background of theirs, and at the same time, set up featured courses with consideration of school-specific characteristics. For example, the school of machinery engineering can offer machine product design under its industrial design program.

Set up traditional Chinese culture courses. Chinese traditional culture is extensive and profound. We should not just imitate what the west has done in industrial design, but should integrate the Chinese local folk arts into the courses. Universities should offer traditional Chinese culture courses to enhance students' capacity of innovation and cultural sentiments.

Enrich content and form of design practice. In order to cultivate practical and project experiences of students, universities should offer practice content in the design courses, and at the same time, arrange design competitions for students, and construct off-campus practice basis so that students can learn from the projects and enhance their capacity of comprehensive utilization of knowledge and skills.

Optimization of evaluation SYSTEM of Chinese and western cultural integration and counter-measure analysis

Increase investment in teaching resource. Universities should ensure integrity of faculty and make reasonable adjustment to the recruitment standards for teachers. They should employ partial faculty from industry and companies, expand teaching resources for industrial design, and set up practice basis.

Flexible adjustment of teaching objectives according to actual conditions. Teaching objectives should not be static. Universities should make timely and accurate adjustments to the teaching objectives upon changes in the university's infrastructure, actual conditions of the university and society's needs for talents.

Diversify teaching methods. "One-way Input + Three-part Approach" is adopted by a majority of universities and schools in China. We should learn from diversified teaching methods featuring "studentorientation" in the west, such as studio-tutorial system, discussion-based teaching, university-companyuniversity teaching method, and enable students to learn better in an environment featuring integration of professional knowledge and practice. 
Optimization of teaching mode of Chinese and western cultural integration and counter-measure analysis

Set diversified and flexible evaluation criteria. Evaluation criteria should not be uniformly determined by the course designers, in order to motivate students to learn. Their personal differences should be respected by taking varied evaluation standards. We should set up clear goals in line with their actual conditions and try to avoid overly high or low goals that will end up discourage students.

Use personalized and diverse evaluation methods. Examination approach should also be personalized. Test results should be used to motivate students, rather than serving as ultimate indicators of student's capacity. We should compare students' works at different times so that teachers can better understand how students are performing over their learning process.

Construct multi-variation evaluation subject. To break the limitations of evaluation system centered on teachers, we should introduce students and companies into an evaluation system that comprehensively evaluates students' learning and design works from varied aspects. In this way, evaluation results will be objective and fair.

\section{Conclusion}

Currently China's industrial design education fails to meet demands of integrated global economy. This paper tries to combine advanced western education concepts with China's industrial design education, and studies the education system in China. We have below conclusions:

(1) The curriculum, teaching mode, and evaluation system should be treated as an organized whole rather than independent parts by researchers. Comprehensive study and analysis on the Chinese and western industrial design education is conducted, and German system is selected as a representative of western education.

(2) Through comparative analysis, it is concluded that Chinese education system has deficiencies in lacking featured curriculum, homogenours teaching mode, lack of personalization and objectivity in evaluation.

(3) To address such deficiencies in the Chinese industrial design education system, we have proposed corresponding advices and counter-measures with consideration of the advantages in the western education system.

\section{References}

Boks, C. \& Diehl, J. C. (2006). Integration of sustainability in regular courses: Experiences in industrial design engineering. Journal of Cleaner Production, $\quad$ 14(9), https://dx.doi.org/10.1016/j.jclepro.2005.11.038

Hu, J. \& Cardin, M. A. (2015). Generating flexibility in the design of engineering systems to enable better sustainability and lifecycle performance. Research in Engineering Design, 26(2), 121-143. 
Chen / Construction of Industrial Design Education System with Consideration...

http://dx.doi.org/10.1007/s00163-015-0189-9

Hutchison, H. F. (1964). Education for industrial design. Nature, 202(4935), 934-934. http://dx.doi.org/10.1038/202934a0

Mahmoud, G. (2014). Philosophy of researches unit establishing for the industrial design to support the relation between the education \& industry. Cancer Genetics, 207(3), 75-82. http://dx.doi.org/10.1016/j.cancergen.2014.02.008

Naveiro, R. M. \& Pereira, R. C. D. S. (2008). Design education in Brazil. Design Studies, 29(3), 304-312. http://dx.doi.org/10.1016/j.destud.2008.02.002

Sener, C. J. \& Kotch, R. A. (2007). The bell system center for technical education: one industry's university. IEEE Transactions on Education, 15(2), 103-108. http://dx.doi.org/10.1109/TE.1972.4320732

Tenorio, M. F. D. M., Maia, A. C. P. \& Grant-Tenorio, A. E. (2002). A model for advanced in-house industrial training: a case study on intelligent system technology transfer using a project-oriented approach. IEEE Transactions on Education, 40(2), 144-153.

Yang, M. Y., You, M. \& Chen, F.C. (2005). Competencies and qualifications for industrial design jobs: implications for design practice, education, and student career guidance. Design Studies, 26(2), 155-189. http://dx.doi.org/10.1016/j.destud.2004.09.003

Yao, W. (2015). Approaching Chineseness: investigating the cultural transfer of behavioural factors in and through Chinese industrial design. Journal of Information Science, 36(4), 517-529. http://dx.doi.org/10.1177/0165551510374006

Zainol, A. S., Azahari, M. H. H., Mastor, K. A., Sanusi, Z. M. \& Yusof, W. Z. M. (2015). Brainstorming in industrial design education: Is there mediation effect?. International Geology Review, 18(2), 167-171. http://dx.doi.org/10.1080/00206817609471186 